\title{
Spor Bilimleri, İlahiyat ve Müzik Eğitimi Öğrencilerinin İyi Oluş Durumlarının Karşılaştırılması
}

\author{
Hatice Onuray Eğilmez a,
}

\section{Özet}

'İyi oluş' insanın kendi hayatındaki durumunu nasıl gördügüule ilgili bir kavramdır. Araştırma müziğin, ibadetin ve bedensel aktivitenin iyi oluşa etki etme durumu ile ilgili fikir edinebilme amacıyla yapılmıştır. Araştırmaya Bursa Uludağ Üniversitesi Eğitim Fakültesi Müzik Eğitimi Anabilim Dalında $(n=86)$, İlahiyat $(n=97)$ ve Spor Bilimleri Fakültesinde $(n=79)$ okuyan öğrenciler $(n=262)$ dâhil edilmiştir. Veriler, iyi oluş ölçeği (PERMA) ile toplanmıştır. PERMA puanının yıllara ve fakülteye göre durumuna ilişkin verilerin analizinde ANOVA, GANO ile ilişkisinin analizinde Pearson Korelasyon katsayısı ve cinsiyete göre ilişkisinin analizinde ise t-testi kullanılmıştır. Araştırmada diğer bölümlerden daha fazla spor ile uğraşan Spor Bilimleri Fakültesi öğrencilerinin diğer iki gruptan anlamlı olarak daha yüksek iyi oluş puanlarına sahip oldukları görülmüştür. Spor Bilimleri Fakültesi öğrencilerinin Olumlu Duygular, Bağlanma, Anlam ve Başarı alt boyut puanlarının da diğer öğrencilerden anlamlı olarak daha yüksek olduğu tespit edilmiştir. Öğrencilerin cinsiyet, GANO ve eğitim yılı değişkenlerine göre iyi oluş durumlarında istatistiksel olarak anlamlı bir fark bulunmamıştır.
Anahtar Kelimeler

İbadet

İyi oluş

Müzik

Spor

\section{Makale Hakkında}

Geliş Tarihi: 28.02.2020

Kabul Tarihi: 25.12.2020

Doi: 10.18026/cbayarsos.695929

\section{Comparison of the Well-Being of Students of Sports Sciences, Theology and Music Education}

\begin{abstract}
'Well-being' is a concept related to how one sees the situation in his own life. The research was carried out in order to get an idea about the effect of music, worship and physical activitymon well-being. Students $(n=262)$ studying in Bursa Uludağ University, Department of Music Education ( $\mathrm{n}=86)$, Theology $(\mathrm{n}=97)$ and Sport Sciences $(\mathrm{n}=79)$ were included in the study. Data were collected by well-being scale (PERMA). In analyzing the data ANOVA, t-test Pearson Correlation coefficient was used. In the study, it was found that the students of the Faculty of Sport Sciences who deal with more sports than other departments have significantly higher well-being scores than the other two groups. It was determined that the Positive Emotions, Engagement, Meaning and Accomplishment sub-dimension scores of the Faculty of Sports Sciences students were significantly higher than other students. There was no statistically significant difference in students' well-being according to gender, academic grade-point averages and education year variables.
\end{abstract}

Keywords

Worship

Well-being

Music

Sport

\section{About Article}

Received: 28.02.2020

Accepted: 25.12.2020

Doi: 10.18026/cbayarsos.695929

a İletişim Yazarı: haticeegilmez@gmail.com

b Doç. Dr., Uludağ Üniversitesi, Eğitim Fakültesi Güzel Sanatlar Eğitimi Bölümü, Nilüfer, Bursa. ORCID: 0000-0002-4880-2200 


\section{Giriş}

'İyi oluş' insanın hayatındaki durumunu nasıl gördüğüyle ilgili bir kavramdır. Öncelikle fiziksel iyi oluşu çağrıştırsa da 'iyi oluş', fiziksel, zihinsel ve ruhsal durumun tümünü kapsamakta, "bireyin bedensel, zihinsel ve ruhsal açıdan bir bütünlük içinde tam işlevde bulunarak iyi olma ve sağlıklılık halini yakalaması ve bu şekilde toplumsal ve doğal çevrede en verimli şekilde yaşamını sürdürmesi" (Myers, Sweeney ve Witmer, 2000) olarak ifade edilmektedir.

Eski Yunandan bu yana hatta öncesinde insanların var oluşlarından itibaren 'iyi yaşamın' doğasını merak ettikleri (Diener, 2009), iyi olabilmenin yollarını arayarak, kendilerini iyi hissetmek ve iyi etkinliklerde bulunmak adına çaba içinde oldukları bilinmektedir. Bu çaba, geçtiğimiz yüzyılda yapılan olumlu duygulardan ziyade olumsuz duyguların tespitine yönelik araştırmaların (Demirci ve Ekşi, 2015) yanı sıra 'iyi oluşun' pozitif psikoloji biliminin çalışma alanları arasında yer almasında belirleyici olmuştur. Temel amacı sadece rahatsızlıkların azaltılması olan psikoterapi de son dönemlerde iyi oluşun nasıl daha da yükseltilebileceğine odaklanmıştır (Carr, 2016).

İyi oluş özelliklerine göre farklı görüş ve felsefi yaklaşımlardan hareketle ele alınarak, 'iyi oluş', 'öznel iyi oluş', 'psikolojik iyi oluş', 'duygusal iyi oluş', 'ruhsal iyi oluş', 'kişisel iyi oluş' gibi alt kavramlarla temellendirilmiştir (Türkmen, 2012). Küçük ve Çakıcı'ya (2018) göre de iyi oluşla ilgili yapılan araştırmalarda iyi oluş genel kavramının yanında öznel iyi oluş, psikolojik iyi oluş, iyilik hali (wellness), yaşam kalitesi, yaşam doyumu ve olumlu duygulanım gibi çeşitli kavramların yer aldığı görülmektedir. Dünya Sağlık Örgütünün sağlık tanımına dayanan 'iyi olma' kavramı yukarıda bahsi geçen kavramları barındırmaktadır (Kardaş ve Yalçın, 2019). Dünya sağlık örgütü iyi oluşun öznel ve nesnel olmak üzere iki boyutta var olduğunu belirtmekte, iyi oluşun bireyin yaşam deneyimlerini, yaşam koşullarının sosyal norm ve değerlerle karşılaştırılmasını içerdiğini ifade etmektedir (Department of Health, n.d). Tanımda bahsi geçen nesnel yaklaşımın, iyi bir yaşamın bileşenlerini incelediği, öznel yaklaşımın ise insanların yaşamlarının öznel değerlendirmelerini incelediği (Western ve Tomaszewski, 2016) belirtilmektedir.

Alanyazın incelendiğinde iyi oluşun 'öznel iyi oluş' ve 'psikolojik iyi oluş' gibi iki genel yaklaşım ile ifade edildiği görülmektedir. Pozitif psikoloji alanında çalışan bilim insanlarından biri olan Ryff (1989) psikolojik iyi oluşu, bireylerin kendilerini kabul edebilmeleri, çevrelerini etkin bir şekilde kullanarak olumlu ilişkiler kurabilmeleri, özerk düşünceye ve yaşamda bir amaca sahip olarak kendilerini geliştirebilmeleri üzerine temellendirmiştir. Öznel iyi oluş ise, bireylerin yaşamlarından aldıkları doyumları ve hazları ifade etmektedir. Diener'e (1984) göre bireyler, olumlu duyguları sıklıkla yaşadıkları, olumsuz duyguları çok az deneyimledikleri ve yaşamlarından doyum aldıkları zaman kendilerini öznel açıdan daha iyi hissetmektedirler.

Seligman farklı bileşenleri bir araya getirerek çok boyutlu iyi oluş modeli üzerinde durmakta ve bireylerin mutluluğa erişebilmeleri için beş yol önermektedir. Seligman (Akt. D'raven ve Pasha-Zaidi, 2016) birinci yolun, keyifli yaşam için 'olumlu duyguların' en üst düzeye çıkmasıyla, ikinci yolun zamanın nasıl geçtiğini anlamayacak kadar kendini bir etkinliğe kaptırmak olarak tanımlanabilecek 'hayata bağlanmayla', üçüncü yolun hayatın amacı ve anlamlıyla ilgili, insana yaşamanın değerli ve yaşanmaya değer olduğu hissi veren 'anlamlı yaşam' ile, dördüncü yolun başkaları tarafından sevilmek ve değer görmeyle neticelenen 
'olumlu ilişkiler' ile ve beşinci yolun ise öz-yeterliği beraberinde getirdiğine inanılan 'başarı' ile elde edilebileceğine vurgu yapmaktadır.

Ryff (1989), Seligman'ın modeline paralel olarak iyi oluş haline sahip olan bireylerin kendine karşı düşüncelerinin olumlu olduğunu, sağlam insan ilişkilerine sahip olduklarını, kendi kararlarını kendilerinin verebildiğini, kişisel gelişimlerine değer verdiklerini, yaşamın anlamının olduğuna inandıklarını ve zorluklarla başa çıkma becerilerinin yüksek olduğunu belirtmektedir.

Kendini iyi hisseden bireylerin daha mutlu olma eğiliminde oldukları, hayatlarına iyi bir şekilde yön vermek için daha motive oldukları bilinmektedir. İyi hisseden bireylerin iş yerinde daha iyi performans sergiledikleri, daha işbirlikçi oldukları, tatmin edici ilişkiler kurdukları, güçlü bağışıklık sistemine, daha iyi fiziksel sağlığa, öz düzenleme ve başa çıkma yeteneklerine sahip oldukları, daha uzun yaşadıkları, daha az uyku problemlerinin olduğu, tükenmişlik düzeylerinin düşük olduğu ve daha kontrollü oldukları tespit edilmiştir (Perma, n.d). Zayıf bir iyi oluş duygusuna sahip olmanın ise insanın üretkenliğini sınırlandırdığı belirtilmektedir. Görülmektedir ki bireylerin iyi oluşları ülke ekonomileri ve politikalarını dahi etkileyecek nitelikte olabilmektedir.

Alan uzmanları, günümüzde de oldukça yaygınlaşan depresyon ve kaygı gibi bozuklukların sebepleri yanı sıra, mutluluk, öz saygı, iyimserlik gibi iyi oluşun diğer unsurlarını araştırmakta (Yalçın, 2014) bu noktada iyi oluşa etki edebilecek unsurlar üzerinde durmaktadırlar. İyi oluşta sağlı̆̆ın yanı sıra yeterlik duygusu, başkalarıyla ilişkiler, iyimserlik, ekonomik durum gibi hususların da etkin olduğu belirtilmektedir. Birçok faktör arasında müziğin, ibadetin ve bedensel aktivitenin bireylerin iyi oluşlarına olumlu etki edebileceğine inanılmakta, alan yazında bu yönde araştırmalara rastlanmaktadır.

Rickard ve Mcferran (2011) müziğin bireylerin ve toplumun iyi oluşu için çok önemli olduğunu, fiziksel ve zihinsel sağlı̆̆ geliştirmek için resmi bağlamda kullanılabileceğini belirtmektedirler. Günümüzde de müzik, tıp doktorları tarafından ağrıyı, stresi yönetme noktasında tıbbı ortamlarda giderek fazla kullanılmakta iken, sınıf içerisinde bilişsel ve psikososyal iyi oluşu artırmak için de eğitimciler tarafından kullanılmaktadır (Rickard ve Mcferran, 2011). Alanyazında her ne kadar türüne göre etki durumu değişiklik gösterse de (Sezer, 2013) bireylerin müzikle meşgul olmalarının iyi oluş etkisini artırdığını ortaya koyan birçok araştırmaya rastlanmaktadır (Bieligmeyer, Helmert, Hautzinger ve Vagedes, 2018; Lee, Krause, Davidson, 2017; Greaves ve Farbus, 2006; Hays, 2005; Ploukou ve Panagopoulou, 2018).

Müziğin yanı sıra ibadetin de bireylerin iyi oluşunda etkili olduğunu ortaya koyan araştırmalar bulunmaktadır. Sharma ve Singh (2019) dinin, her insanın kültüründe bir biçimde mevcut olduğunu, önemine yönelik şüpheciliğin artmasına rağmen maneviyatın, fiziksel ve psikolojik iyi oluş ile tutarlı bir şekilde ilişkilendirildiğini belirtmektedirler. Dine bağlılığın, ibadet etmenin, pozitif mutluluk ve memnuniyetle ilgili olduğu, dindar insanların olumsuz durumların üstesinden gelip daha iyi mücadele edebildiklerine inanılmaktadır. Ellison'a (1991) göre dindar insanların Tanrı'ya ve inanca yakın olma duyguları coğrafyadan coğrafyaya farklılık gösterse dahi mutluluğun kaynağını oluşturmaktadır. Araştırmalar dini ve manevi inançlarına daha fazla bağlı olan bireylerin olmayanlara göre daha mutlu, sağlıklı olduklarını ortaya koymaktadır (Akt. Sharma ve Singh, 2019). Yapılan alanyazın taramasında bu bulguyu destekleyen çalışmalara rastlanmıştır (Khalek ve Ahmed, 2009; Kokmaz Erdoğruca, 2012; 
Tiliouine, Cummins ve Davern, 2009). Nitekim, Koenig, McCullough ve Larson (2001) geniş bir alanyazın incelemesinde, bu konuda yapılan çalışmaların \% 79'unun dindarlık ve iyi oluş arasında anlamlı ve pozitif bir ilişki olduğunu vurgulamışlardır.

Alanyazında müzik ve ibadetin yanı sıra güçlü fiziksel aktivitenin bireylerin iyi oluşlarına yönelik potansiyel faydalarını ortaya koyan araştırmalara da rastlanmaktadır (Costigan, Lubans, Lonsdale, Sanders ve Cruz, 2019; Jin, Carson, Pabayo, Spence, Tremblay ve Lee, 2019; Panza, Taylor, Thompson, White ve Pescatello, 2019).

Araştırmada müziğin, ibadetin veya fiziksel aktivitenin, bireylerin iyi oluş düzeylerine etkisi merak konusu olmuştur. Bu bağlamda gününün yoğun bir kısmını müzikle geçiren üniversite Müzik Eğitimi Anabilim Dalı öğrencilerinin, diğer bölümlerden daha fazla spor ile meşgul olan Spor Bilimleri Fakültesi öğrencilerinin ve diğer bölümlerdeki öğrencilerden daha fazla ibadet eden İlahiyat Fakültesi öğrencilerinin iyi oluş durumları araştırılmıştır. Araştırmada aşağıda yer alan sorulara cevap aranmaya çalışılmıştır:

1. Müzik Eğitimi Anabilim Dalı ile Spor Bilimleri Fakültesi ve İlahiyat Fakültesi öğrencilerinin iyi oluşları öğrenim yılına göre değişiklik göstermekte midir?

2. İyi oluş ile genel akademik not ortalaması (GANO) arasında anlamlı bir ilişki var mıdır?

3. İyi oluş cinsiyete göre farklılık göstermekte midir?

4. Müzik Eğitimi Anabilim Dalı, Spor Bilimleri Fakültesi ve İlahiyat Fakültesi öğrencilerinin iyi oluşları arasında anlamlı farklılık var mıdır?

\section{Araştırmanın Amacı}

Araştırmada Müzik Eğitimi Anabilim Dalı, Spor Bilimleri Fakültesi ve İlahiyat Fakültesi öğrencilerinin iyi oluş durumlarının karşılaştırılması, bu vesileyle müziğin, ibadetin veya fiziksel aktivitenin, bireylerin iyi oluş düzeylerine etkisi ile ilgili fikir sahibi olabilmek amaçlanmıştır.

\section{Araştırmanın Önemi}

Günümüzde kapitalist sistemin bireyler üzerinde oluşturduğu baskı, yoğun mesai saatleri, bireyleri bedensel ve ruhsal olarak olumsuz etkilemektedir. Bireylerin iyi oluşlarında etkili olabilecek unsurlar olan müzik, ibadet ve fiziksel aktivite üzerinde duran bu araştırma, elde edilen veriler doğrultusunda bireylerin iyi oluşlarında hangi etkinliğin daha etkili olabileceğini ortaya koymaktadır. Ülke politikalarına da doğrudan etki eden bireylerin iyi oluş durumlarının olumlu yönde geliştirilebilmesi için araştırma sonuçlarının faydalı olacağına inanılmaktadır. Yapılan alan yazın taramasında her üç aktivitenin de iyi oluş üzerine etkilerini ortaya koyan çalışmalar dikkat çekerken her üç aktiviteden hangisinin daha etkili olabileceğine dair çalışmalara rastlanmamış olması mevcut araştırmayı önemli kılmaktadır. 


\section{Yöntem}

\section{Araştırmanın Modeli}

Araştırmada keşfedici korelasyonel araştırma deseni kullanılmıştır. Keşfedici korelasyonel araştırmalar, iki veya daha fazla değişken arasında birlikte değişim olup olmadığını, birlikte değişim varsa bu değişimin derecesinin hangi düzeyde olduğunu belirlemeyi amaçlayan araştırmalarda kullanılan değişkenler arası ilişkileri çözümleyerek önemli bir olayı anlamaya çalışmak için kullanılmaktadırlar (Büyüköztürk, Kılıç Çakmak, Akgün, Karadeniz ve Demirel, 2014). Bu nedenle seçilen modelin araştırmanın yöntemine uygun olduğu düşünülmektedir.

\section{Örneklem}

Araştırmaya Uludağ Üniversitesi Eğitim Fakültesi Müzik Eğitimi Anabilim Dalında okuyan 86 öğrenci, İlahiyat Fakültesinde okuyan 97 öğrenci ve Spor Bilimleri Fakültesinde okuyan 79 öğrenci olmak üzere toplam 262 öğrenci (Tablo 1) katılmıştır. Örneklem belirlenirken müziğin, ibadetin veya beden aktivitesinin iyi oluşa etkisi ile ilgili fikir sahibi olabilmek için gününün çoğunluğunu müzikle geçiren Müzik Eğitimi Anabilim dalı öğrencileri, bedensel aktivitenin diğer bölümlere oranla daha çok olabileceğine inanılan Spor Bilimleri Fakültesi öğrencileri ve ibadeti daha yoğun yaşadığına inanılan İlahiyat Fakültesi öğrencileri seçilmiştir. Her sınıf düzeyinden rastgele seçilerek ölçeği yanıtlayan tüm öğrencilere hangi sıklıkla ibadet ettikleri, spor yaptıkları ve herhangi bir müzik etkinliğinde bulundukları da sorularak örneklem grubunu oluşturan öğrencilerin bedensel aktivite, müzik ve ibadet etme düzeylerinden emin olunması amaçlanmıştır.

Tablo 1. Örneklem Grubuna Ait Betimsel İstatistikler

\begin{tabular}{|c|c|c|c|c|c|c|c|c|c|}
\hline & & \multicolumn{2}{|c|}{ İlahiyat } & \multicolumn{2}{|c|}{ Beden } & \multicolumn{2}{|c|}{ Müzik } & \multicolumn{2}{|c|}{ Toplam } \\
\hline & & $\mathbf{f}$ & $\%$ & f & $\%$ & f & $\%$ & $\mathbf{f}$ & $\%$ \\
\hline \multirow[t]{3}{*}{ Cinsiyet } & $\mathrm{K}_{1 z}$ & 65 & 67 & 39 & 49 & 51 & 59 & 155 & 59 \\
\hline & Erkek & 32 & 33 & 40 & 51 & 35 & 41 & 107 & 41 \\
\hline & Toplam & 97 & 100 & 79 & 100 & 86 & 100 & 262 & 100 \\
\hline \multirow[t]{6}{*}{ Öğr. Yılı } & 1 & 8 & 8 & 20 & 25 & 16 & 19 & 44 & 17 \\
\hline & 2 & 22 & 23 & 19 & 24 & 22 & 26 & 63 & 24 \\
\hline & 3 & 19 & 20 & 20 & 25 & 21 & 24 & 60 & 23 \\
\hline & 4 & 31 & 32 & 18 & 23 & 21 & 24 & 70 & 27 \\
\hline & 5 & 17 & 18 & 2 & 3 & 6 & 7 & 25 & 10 \\
\hline & Toplam & 97 & 100 & 79 & 100 & 86 & 100 & 262 & 100 \\
\hline \multirow[t]{2}{*}{ İbadet } & Hiç & 2 & 2 & 34 & 43 & 68 & 79 & 104 & 40 \\
\hline & $\mathrm{Az}$ & 4 & 4 & 28 & 35 & 14 & 16 & 46 & 18 \\
\hline
\end{tabular}




\begin{tabular}{lllllllll} 
Çok & 91 & 94 & 17 & 22 & 4 & 5 & 112 & 43 \\
\hline Toplam & 97 & 100 & 79 & 100 & 86 & 100 & 262 & 100
\end{tabular}

Tablo 1. devam

\begin{tabular}{|c|c|c|c|c|c|c|c|c|c|}
\hline & & \multirow{2}{*}{\multicolumn{2}{|c|}{ İlahiyat }} & & & & & & \\
\hline & & & & \multicolumn{2}{|c|}{ Beden } & \multicolumn{2}{|c|}{ Müzik } & \multicolumn{2}{|c|}{ Toplam } \\
\hline & & f & $\%$ & $\mathrm{f}$ & $\%$ & f & $\%$ & $\mathrm{f}$ & $\%$ \\
\hline \multirow[t]{4}{*}{ Spor } & Hiç & 53 & 55 & 4 & 5 & 41 & 48 & 98 & 37 \\
\hline & $\mathrm{Az}$ & 39 & 40 & 29 & 37 & 36 & 42 & 104 & 40 \\
\hline & Çok & 5 & 5 & 46 & 58 & 9 & 10 & 60 & 23 \\
\hline & Toplam & 97 & 100 & 79 & 100 & 86 & 100 & 262 & 100 \\
\hline \multirow[t]{4}{*}{ Müzik } & Hiç & 55 & 57 & 43 & 54 & 0 & 0 & 98 & 37 \\
\hline & $\mathrm{Az}$ & 32 & 33 & 21 & 27 & 19 & 22 & 72 & 27 \\
\hline & Çok & 10 & 10 & 15 & 19 & 67 & 78 & 92 & 35 \\
\hline & Toplam & 97 & 100 & 79 & 100 & 86 & 100 & 262 & 100 \\
\hline
\end{tabular}

\section{Veri Toplama Araçları}

Araştırmada veri toplama araçları olarak, 'Perma iyi oluş ölçeği formu' ve 'öğrenci demografik bilgi formu' kullanılmış olup, bu formlara ilişkin bilgiler aşağıda ele alınmıştır.

\section{Perma İyi Oluş Ölçeği Formu}

Martin Seligman'ın iyi oluş ile ilgili beş boyutlu ( $\mathrm{P}=$ positive emotions=olumlu duygular, $E=$ engegament=bağlanma, $\mathrm{R}=$ positive relationships=olumlu ilişkiler, $\mathrm{M}=$ =meaning=anlam ve A=accomplishment=başarılar) kavramsallaştırmasını ölçüme dökmeyi amaçlayan ölçek Butler ile Kern tarafından geliştirilmiştir. Ölçek, Demirci, Ekşii, Dinçer ve Kardaş (2017) tarafından geçerlik ve güvenirliği yapılarak Türkçeye uyarlanmıştır. PERMA Ölçeği iyi oluş modelinin bileşenlerini ölçen 15 madde ve 8 dolgu maddesi olmak üzere 23 maddeden oluşmaktadır. 15 maddelik ölçekte her boyutta 3 madde bulunmaktadır. Alt boyutların puanları ilgili alt boyuttaki 3 maddenin ortalaması alınarak hesaplanmaktadır: $\mathrm{P}$ olumlu duygular: (p5+p10+p22)/3, E bağlanma: (p3+p11+p21)/3, R olumlu ilişkiler: $(\mathrm{p} 6+\mathrm{p} 15+\mathrm{p} 19) / 3, \mathrm{M}$ anlam: $(\mathrm{p} 1+\mathrm{p} 9+\mathrm{p} 17) / 3, \mathrm{~A}$ başarılar: (p2+p8+p16)/3. Demirci ve diğerlerinin (2017), orijinal formdaki 15 maddeli ve 5 alt boyutlu ölçme modeline uygun olarak Türkçe versiyonunu doğrulayıcı faktör analizi ile incelemişlerdir. Ölçeğin faktör yükleri .42 ile .89 arasında değiştiği görülmüş ve beş boyutlu modelinin kabul edilebilir düzeyde uyum verdiği sonucuna ulaşılmıştır. Mevcut çalışmada da ölçekteki bu boyutları gösteren maddeler analizlere dâhil edilmiştir. Demirci ve diğerlerinin (2017), çalışmalarında Cronbach alpha iç tutarlılık katsayısını ölçeğin toplam puanı için .91, olumlu duygulanım alt boyutu için .81, bağlanma alt boyutu için .61, ilişkiler alt boyutu için .61, anlam alt boyutu için .77, başarı alt boyutu için .70 olarak hesaplamışlarıdır. 
Mevcut çalışmada Cronbach alpha iç tutarlılık katsayısı ölçeğin toplam puanı için .91, olumlu duygular alt boyutu için .82, bağlanma alt boyutu için .63, olumlu/ iyi ilişkiler alt boyutu için .67 , anlam alt boyutu için .81 , başarı alt boyutu için .73 olarak hesaplanmıştır.

Ölçeğin alt boyutları;

(P) Olumlu duygular: Neşe gibi olumlu duyguları yaşamak. Çevreyi olumlu bir şekilde algilamak.

(E) Bağlanma: Okul, organizasyon vb. için gerçekleştirilen faaliyetlerle zamanın nasıl geçtiğini anlamayacak kadar bağlantı kurmak.

(R) Olumlu/ iyi ilişkiler: Başkaları tarafından destek ve değer görmek.

(M) Anlam: Hayatının değerli olduğuna inanmak. Anlam, yaşamın amacını sorgular ve duygularımızla aramızda bir köprü görevi görür.

(A) Başarı: Kendi belirlediği yaşam / iş hedeflerinde bir başarı hissi yaşamak (Singh \& Raina, 2019).

\section{Öğrenci Demografik Bilgi Formu}

Üniversite öğrencilerinin demografik özelliklerine ilişkin bilgiler geliştirilen, 'Öğrenci Demografik Bilgi Formu' ile toplanmıştır. Bu bilgi formunda, öğrencilerin cinsiyeti, sınıf düzeyi, akademik not ortalaması, hangi sıklıkla ibadet ettikleri, spor yaptıkları ve enstrüman çalma, şarkı söyleme gibi müziksel etkinlikte bulunduklarına ilişkin sorular yer almıştır.

\section{Verilerin Toplanması ve Analizi}

Verilerin toplanmasında Bursa Uludağ Üniversitesi Sosyal ve Beşeri Bilimler Araştırma ve Yayın Etik Kurulundan 06.09.2019 tarihinde 2019-07 sayılı oturumunda elde edilen 13.09.2019 tarih ve 26468960-044/32523 sayılı izin alındıktan sonra katılımcılara araştırmanın amacı konusunda bilgi verilmiş ve uygulamalar, okul ortamında öğrencilerin ders aralarında veya boş zamanlarında araştırmacı tarafından gerçekleştirilmiştir.

PERMA puanının yıllara göre değişim durumu ve PERMA ile alt boyutlarının fakülteye göre değişim durumuna ilişkin verilerin analizinde tek yönlü ANOVA testi kullanılmıştır. GANO ile PERMA puanları arasındaki ilişkinin belirlenmesi için Pearson korelasyon katsayısı hesaplanmıştır. PERMA puanlarının cinsiyete göre değişim durumuna ilişkin verilerin analizinde ise bağımsız örneklemler t-testi kullanılmıştır. 


\section{Bulgular}

Tablo 2. PERMA Puanının Öğrenim Yıllarına Göre Değişim Durumuna İlişkin ANOVA Tablosu

\begin{tabular}{llllll}
\hline Y11 & $\mathbf{N}$ & M & SD & F & p \\
\hline 1 & 44 & 7,11 & 1,19 & 2,055 & 0,087 \\
2 & 63 & 7,17 & 1,12 & & \\
3 & 60 & 6,98 & 1,39 & & \\
4 & 70 & 6,73 & 1,57 & & \\
5 & 25 & 6,37 & 1,72 & & \\
\hline
\end{tabular}

Tablo 2' de PERMA puanının öğrenim yıllarına göre değişim durumuna ilişkin bulgular yer almaktadır. Buna göre genel olarak ilerleyen yıllardaki PERMA puanları ilk yıllara göre daha düşük gibi görünmekle birlikte bu farklılık anlamlı bulunmamıştır, $F(4,257)=2,055$, p = 0,087.

Tablo 3. PERMA ve GANO İlişkisini Gösteren Pearson Korelasyon Tablosu

\begin{tabular}{lll}
\hline & Pearson $\mathrm{r}$ & $\mathrm{p}$ \\
\cline { 2 - 3 } PERMA-GANO & $-0,013$ & 0,864 \\
\hline
\end{tabular}

GANO ile PERMA puanları arasındaki korelasyon istatistiksel olarak anlamlı bulunmamıştır (tablo 3), $r=-0,013, p=0,864$. PERMA puanlarındaki varyansın GANO ile açılanamayacağ söylenebilir.

Tablo 4. PERMA Puanlarının Cinsiyete Göre Değişimini Gösterir T-Testi Tablosu

\begin{tabular}{lllllll}
\hline Cinsiyet & $\mathbf{N}$ & $\mathbf{M}$ & SD & $\mathbf{t}$ & $\mathbf{d f}$ & $\mathbf{p}$ \\
\hline Kiz & 155 & 6,99 & 1,39 & 0,931 & 260 & 0,353 \\
Erkek & 107 & 6,82 & 1,41 & & & \\
\hline
\end{tabular}

Tablo 4'te görüldüğü üzere PERMA puanları cinsiyete göre değişmemektedir, $\mathrm{t}(260)=0,931$, $\mathrm{p}=0,353$

Tablo 5. PERMA ve Alt Boyutlarının Öğrenim Görülen Alana Göre Değişimini Gösteren ANOVA Tablosu

\begin{tabular}{|c|c|c|c|c|c|c|c|}
\hline & & $\mathrm{N}$ & M & SD & F & $\mathrm{p}$ & Anlamlı Fark \\
\hline \multirow[t]{2}{*}{ PERMA } & İlahiyat & 97 & 6,80 & 1,38 & 6,194 & 0,002 & $\dot{\mathrm{I}}<\mathrm{S}, \mathrm{M}<\mathrm{S}$ \\
\hline & Spor & 79 & 7,37 & 1,13 & & & \\
\hline
\end{tabular}




$\begin{array}{llllllll} & \text { Müzik } & 86 & 6,65 & 1,55 & & & \\ \text { P } & \text { Illahiyat } & 97 & 6,76 & 1,71 & 7,149 & 0,001 & \text { M<S } \\ \text { Spor } & 79 & 7,30 & 1,57 & & & \\ \text { Müzik } & 86 & 6,28 & 1,9 & & & \\ & & & & & & & \\ \text { E } & 97 & 7,10 & 1,54 & 3,930 & 0,021 & \text { ÍS, M<S } \\ & \text { Illahiyat } & 79 & 7,67 & 1,41 & & & \\ & \text { Spor } & 86 & 7,06 & 1,7 & & & \end{array}$

Tablo 5. devam

\begin{tabular}{|c|c|c|c|c|c|c|c|}
\hline \multirow{4}{*}{$\mathrm{R}$} & & $\mathrm{N}$ & M & SD & F & $\mathrm{p}$ & Anlamlı Fark \\
\hline & İlahiyat & 97 & 6,79 & 1,93 & 2,167 & 0,117 & \\
\hline & Spor & 79 & 7,19 & 1,51 & & & \\
\hline & Müzik & 86 & 6,62 & 1,91 & & & \\
\hline \multirow[t]{3}{*}{ M } & İlahiyat & 97 & 6,75 & 1,93 & 3,930 & 0,021 & $\mathrm{M}<\mathrm{S}$ \\
\hline & Spor & 79 & 7,36 & 1,40 & & & \\
\hline & Müzik & 86 & 6,64 & 1,93 & & & \\
\hline \multirow[t]{3}{*}{ A } & İlahiyat & 97 & 6,61 & 1,67 & 4,900 & 0,008 & $\dot{\mathrm{I}}<\mathrm{S}, \mathrm{M}<\mathrm{S}$ \\
\hline & Spor & 79 & 7,30 & 1,28 & & & \\
\hline & Müzik & 86 & 6,65 & 1,74 & & & \\
\hline
\end{tabular}

Tablo 5'te PERMA genel ve alt boyutları puanlarının öğrencilerin öğrenim gördükleri bölüme göre değişimi görülmektedir. Buna göre PERMA genel puanları öğrencinin öğrenim gördüğü bölüme göre değişiklik göstermemektedir, $F(2,259)=6,194, p=0,002$. Farkın nerden kaynaklandığını bulmak için yapılan post hoc testlerinde Spor Bilimleri Fakültesi öğrencilerinin diğer iki gruptan da anlamlı olarak daha yüksek puanlara sahip olduğu görülmüştür. Diğer bölümlerden daha fazla spor ile uğraşan Spor Bilimleri Fakültesi öğrencilerinin müzik ve ibadete daha yoğun iştirak eden diğer iki gruptan anlamlı olarak daha yüksek puanlara sahip olduğu söylenebilir.

P (Olumlu duygular) alt boyutu puanları öğrencilerin öğrenim gördükleri bölümlerine göre değişiklik göstermektedir, $F(2,259)=7,149, \mathrm{p}=0,001$. Farkın nerden kaynaklandığını bulmak için yapılan post hoc testlerinde Spor Bilimleri Fakültesi öğrencilerinin Müzik Eğitimi Anabilim Dalı öğrencilerinden anlamlı olarak daha yüksek puanlara sahip olduğu görülmüştür. Bu durumda diğer bölümlerden daha fazla spor ile uğraşan Spor Bilimleri 
Fakültesi öğrencilerinin olumlu duygularının diğer bölümlerden daha fazla müzik etkinliğinde bulunan Müzik Eğitimi öğrencilerinden daha yüksek olduğu görülmektedir.

E (Bağlanma) alt boyut puanlarına bakıldığında puanlarının öğrencilerin öğrenim gördükleri bölümlere göre değişiklik gösterdiği görülmektedir, $F(2,259)=3,930, p=0,021$. Farkın nerden kaynaklandığını bulmak için yapılan post hoc testlerinde yine Spor Bilimleri Fakültesi öğrencilerinin diğer iki gruptan da anlamlı olarak daha yüksek puanlara sahip olduğu görülmektedir. Diğer bölümlerden daha fazla spor ile uğraşan Spor Bilimleri Fakültesi öğrencilerinin okul, organizasyon vb. için gerçekleştirdikleri faaliyetlerle zamanın nasıl geçtiğini anlamayacak kadar bağlantı kurdukları söylenebilir.

R (Olumlu / iyi ilişkiler) alt boyutu puanlarının Müzik Eğitimi Anabilim Dalı, İlahiyat Fakültesi ve Spor Bilimleri Fakültesi öğrencilerinin öğrenim gördükleri bölümlere göre anlamlı olarak değişmediği görülmektedir, $F(2,259)=2,167, p=0,117$.

M (Anlam) alt boyutu puanları öğrencinin öğrenim gördüğü bölümüne göre değişmektedir, $\mathrm{F}(2,259)=3,930, \mathrm{p}=0,021$. Farkın nerden kaynaklandığını bulmak için yapılan post hoc testlerinde bir kez daha Spor Bilimleri Fakültesi öğrencilerinin Müzik Eğitimi Anabilim Dalı öğrencilerinden anlamlı olarak daha yüksek puanlara sahip olduğu görülmektedir. Bu durumda diğer bölümlerden daha çok spor ile uğraşan Spor Bilimleri Fakültesi öğrencilerinin Müzik Eğitimi Anabilim dalı öğrencilerinden daha çok hayatlarının değerli olduğuna inandıkları söylenebilir.

A (Başarı) alt boyutu puanları öğrencinin öğrenim gördüğü bölümüne göre değişmektedir, $\mathrm{F}(2,259)=4,900, \mathrm{p}=0,008$. Farkın nerden kaynaklandığını bulmak için yapılan post hoc testlerinde Spor Bilimleri Fakültesi öğrencilerinin diğer iki gruptan da anlamlı olarak daha yüksek puanlara sahip olduğu görülmüştür. Spor Bilimleri Fakültesi öğrencilerinin kendi belirledikleri yaşam / iş hedeflerinde bir başarı hissi yaşamaları diğer bölümlerdeki öğrencilerden daha yüksek olduğu söylenebilir.

\section{Tartışma, Sonuç ve Öneriler}

Witter, Okun, Stock ve Haring (1984) tarafından eğitimin iyi oluş ile olumlu yönde anlamlı ilişkisi olduğu ortaya konmuştur. Ancak mevcut araştırma bulguları doğrultusunda anlamlı bir farklılık olmasa dahi öğrencilerin ilerleyen yıllardaki PERMA puanlarının ilk yıllara göre daha düşük olduğu görülmektedir. Anlamlı bir değişim olmaması üniversite eğitimleri boyunca öğrencilerin iyi oluş düzeylerinin çok değişiklik göstermediği şeklinde yorumlanabilir.

Araştırma sonuçlarından diğer biri ise GANO ile PERMA puanları arasındaki korelasyondur. Söz konusu puanlar arasındaki korelasyon istatistiksel olarak anlamlı bulunmamıştır. PERMA puanlarındaki varyansın GANO ile açıklanamayacağ 1 ve mevcut araştırma sonucuna göre de akademik başarının iyi oluşla ilgisi olmadığı söylenebilir. Ancak Ateş'in (2016) araştırma sonucunda akademik başarı ile iyi oluş arasında pozitif yönde anlamlı düzeyde ilişki olduğu belirlenmiştir. Ayrıca Quinn ve Duckworth (2007) da araştırmalarında akademik performansın iyi oluşun yordayıcısı olduğunu belirtmişlerdir. Araştırma sonuçları beden eğitimi öğretmenlerinin başarı algısı psikolojik iyi oluş düzeyleri arasında pozitif yönlü ve anlamlı ilişki olduğunu göstermiştir. 
Müzik Eğitimi Anabilim Dalı, İlahiyat Fakültesi ve Spor Bilimleri Fakültesi öğrencilerinin PERMA puanları cinsiyete göre de değişmemektedir. Diğer bir değişle örneklem grubunda yer alan kız ve erkek öğrencilerinin iyi oluşlarında bir farklılık görülmemektedir. Üniversite ortamının öğrencilere sunduğu cinsiyet ayrımcılığından uzak, eşit hak ve imkânlara sahip yaklaşımı mevcut çalışmada elde edilen bulguyu açıklar niteliktedir. Alanyazında mevcut araştırma sonucunu destekleyen ve iyi oluş durumlarıyla cinsiyet arasında fark tespit edemeyen araştırmalara rastlanmaktadır (Dağ, Korkutata ve Özavcı, 2019; Koç ve Keklik, 2020; Tuzgöl Dost, 2014; Türköz ve Şahin Kıralp, 2019)

Mevcut araştırmada Müzik Anabilim Dalı ve İlahiyat Fakültesi öğrencilerinden daha fazla bedensel aktivitede bulunan Beden Eğitimi öğrencilerinin iyi oluş puanlarının diğer öğrencilere kıyasla daha yüksek olduğu görülmektedir. Bedensel aktivitenin iyi oluşla olan pozitif ilişkisi birçok araştırmada ortaya konmuştur (Costigan ve diğerleri, 2019; Downward ve Rasciute, 2011; Jin ve diğerleri, 2019; Panza ve diğerleri, 2019). Her ne kadar alanyazında ibadet ve müziğin de iyi oluşla pozitif ilişkisini ortaya koyan araştırmalar (Greaves ve Farbus, 2006; Hays, 2005; Lee ve diğerleri, 2017; Ploukou ve Panagopoulou, 2018; Bieligmeyer ve diğerleri, 2018; Khalek ve Ahmed, 2009; Tiliouine ve diğerleri, 2009; Kokmaz Erdoğruca, 2012) mevcut olsa da araştırma sonuçları spor ile meşgul olan Spor Bilimleri Fakültesi öğrencilerinin iyi oluş düzeylerinin diğer iki bölüm öğrencilerinden daha yüksek olduğunu göstermektedir. Genellikle özel yetenek (spor, resim, müzik) sinavlarıla girilen bölümlerin merkezi yerleştirmeyle girilen bölümlere kıyasla daha çok arzu edilerek ve hedeflenerek girilen bölümler olduğu bilinmektedir. Bu durum Spor Bilimleri Fakültesi öğrencilerinin iyi oluş düzeylerinin daha yüksek olma nedenini izah edebilir. Bireylerin, yeteneklerine uygun bir bölümü seçmiş olmaları kendilerini daha iyi hissetmelerinde etkili olabileceği düşünülmektedir. Öztürk ve Çetinkaya'nın (2015) araştırmalarında da bölümünü severek ve isteyerek tercih eden katılımcıların olumlu duygu puanlarının bölümünü severek ve isteyerek tercih etmeyen katılımcıların olumlu duygu puanlarından anlamlı biçimde yüksek olduğu tespit edilmiştir. Ancak Müzik Eğitimi Anabilim Dalının da yetenek sınavıyla öğrenci alan bir bölüm olduğu düşünüldüğünde bu noktada Spor Bilimleri Fakültesi öğrencilerinin iyi oluşlarının Müzik Eğitimi Anabilim Dalı öğrencilerinin iyi oluşlarından daha yüksek olmasının nedeninin Spor Bilimleri Fakültelerindeki takım sporlarının varlığıyla açıklamak yerinde olabilir. Toplumsal bir varlık olan bireylerin iyi olmalarında kişiler arası ilişkilerin etkisinin büyük olduğuna inanılmaktadır. Müzik her ne kadar orkestra, koro ve oda müziği gibi grup etkinlikleri ile yapılıyor olsa da müzisyenlerin uzun saatler tek başlarına çalışmaları zorunludur. Müzik Eğitimi Anabilim Dalı öğrencilerinin maruz kaldığı gerek uzun müzik aleti çalışma saatleri gerekse kalabalıklar önünde sergiledikleri solo performansları zaman zaman yıpratıcı olabilmektedir. Spor Bilimleri Fakültesi öğrencileri ile Müzik Eğitimi Anabilim Dalı öğrencileri arasındaki fark bu şeklide açıklanabilir.

Mevcut araştırmada öğrencilerin olumlu duygularına bakıldığında, diğer bölümlerden daha fazla spor ile uğraşan Spor Bilimleri Fakültesi öğrencilerinin olumlu duygularının daha fazla müzik etkinliğinde bulunan Müzik Eğitimi öğrencilerinden daha yüksek olduğu görülmektedir. Diğer bir değişle hayatında spora yer veren öğrencilerin çevreyi diğer öğrencilerden daha fazla olumlu olarak algıladıkları, neşe gibi olumlu duyguları daha çok barındırdıkları söylenebilir. Yaşar Yılmaz ve Çetinkaya'nın (2019) örneklem grubunun yine Uludağ Üniversitesi öğrencilerinden oluşturulan araştırmalarında mevcut araştırma bulgusunu destekleyen bir sonuca ulaşıldığı tespit edilmiştir. Yaşar Yılmaz ve Çetinkaya'nın (2019) araştırmasında da Beden Eğitimi Öğretmenliği bölümü öğrencilerinin olumlu duygu 
puanlarının diğer bölümlerdeki öğrencilerin puanlarından anlamlı biçimde yüksek olduğu belirtilmiştir. Sporun olumsuz duygular ile baş edebilme yöntemleri arasında yer aldığ bilinmektedir. Bu noktada araştırma sonucunun beklenen bir sonuç olduğu söylenebilir.

Yine Spor Bilimleri Fakültesi öğrencilerinin bağlanma puanları göz önünde bulundurulduğunda puanlarının diğer iki bölümdeki öğrencilerin bağlanma puanlarından anlamlı olarak yüksek olduğu görülmektedir. Diğer bir değişle spor ile daha çok meşgul olan Spor Bilimleri Fakültesi öğrencilerinin okul, organizasyon vb. için gerçekleştirdikleri faaliyetlerle zamanın nasıl geçtiğini anlamayacak kadar bağlantı kurdukları söylenebilir. Spor Bilimleri Fakültesi öğrencileri kazanma-kaybetmeye dayalı, yoğun rekabet duygusunun yaşandığı spor aktivitelerinde bulunmaktadırlar. Bu tarz aktiviteler içerisinde yer alan bireylerin yapıkları işleri daha çok benimsemeleri ve bağlantı kurmaları oldukça gerekli bir unsurdur. Araştırma bulgusunun bu düşünceyi destekler nitelikte olduğu söylenebilir.

İnsan sosyal bir varlıktır. İçinde yaşadığı toplum ile iletişimi önemli bir unsur olarak kabul edilmektedir. Bilhassa üniversitede öğrenim gören gençlerin alanı ne olursa olsun çevresiyle olumlu ilişkiler kurması üniversite anlayışının gerekliliğidir. Araştırma bulgularında da bu görüşü destekler nitelikte olumlu / iyi ilişkiler puanlarının öğrencinin bölümüne göre anlamlı olarak değişmediği görülmektedir. Diğer bir değişle başkaları ile olumlu ilişkiler, başkaları tarafından destek ve değer görme durumunda Spor Bilimleri Fakültesi, Müzik Eğitimi Anabilim Dalı ve İlahiyat Fakültesi öğrencileri arasında bir farklılık görülmemektedir.

Diğer bölümlerden daha çok spor ile uğraşan Spor Bilimleri Fakültesi öğrencilerinin 'Anlam' puanlarının Müzik Eğitimi Anabilim dalı öğrencilerinden daha yüksek olduğu diğer bir değişle spor ile meşgul olan Spor Bilimleri Fakültesi öğrencilerinin hayatlarının daha çok değerli olduğuna inandıkları görülmektedir. Her ne kadar bir sporcunun her gün antrenman yapmakla yükümlü olduğu kabul edilse de, bir müzik aleti çalmanın daha titiz ve meşakkatli bir süreç olduğu bilinmektedir. Bu zorlu sürece ister solo, ister toplu performans olsun sahne etkinlikleri de eklenince yıpratıcı neticeler ile karşı karşıya kalınması olası olabilmektedir. Bu durum da Müzik Eğitimi Anabilim öğrencilerinin hayatlarına karşı hissettikleri değer duygusunun azalmasına etken bir unsur olarak kabul edilebilir.

A (Başarı) puanları öğrencinin bölümüne göre değişmektedir. Spor Bilimleri Fakültesi öğrencilerinin diğer iki gruptan da anlamlı olarak daha yüksek puanlara sahip olduğu görülmektedir. Diğer bir değişle Spor Bilimleri Fakültesi öğrencilerinin kendi belirledikleri yaşam / iş hedeflerinde diğer bölümlerdeki öğrencilerden daha fazla bir başarı hissi yaşadıkları söylenebilir. İster bireysel ister takım sporları olsun tüm spor müsabakalarında sporcular başarıya odaklanır. Diğer bölümlerden farklı olarak Spor Bilimleri öğrencileri yarışmaya dayalı her spor etkinliğinde bir başarı hissi yaşamak için mücadele ederler. Spor bilimleri öğrencileri alanları gereği diğer bölümlerdeki öğrencilere kıyasla daha kısa sürede başarı hissini yaşayabilirler. Bu açıdan bakıldığında elde edilen sonucun beklenen bir sonuç olduğu söylenebilir.

Araştırma bulguları spor ile meşgul olan Spor Bilimleri Fakültesi öğrencilerinin iyi oluşlarının daha yoğun müzik ortamı içerisinde bulunan Müzik Eğitimi Anabilim Dalı öğrencileri ve daha çok ibadet eden İlahiyat Fakültesi öğrencilerinden daha yüksek olduğunu ortaya koymaktadır. Araştırma sporun iyi oluşta müzik ve ibadetten daha etkili olduğu ile ilgili bir fikir vermektedir ancak bireylerin iyi oluşlarının sporla, müzikle veya ibadet ile mi daha yüksek olacağının tespitinde ileri araştırmalara ihtiyaç duyulmaktadır. Mevcut araştırmanın 
korelasyonel deseni kullandığı göz önünde bulundurulduğunda neden-sonuç ilişkisi kurma açısından yetersiz olacağı düşünülebilir. Bu bakımdan sporun etkilerinin daha iyi tespit edilebilmesi için deneysel araştırmalara ihtiyaç vardır. Araştırmada elde edilen sonuçlar bireylerin ve paralelinde toplumların iyi oluş düzeylerini artırabilmek üzere bedensel aktiviteden faydanılabeceğini ortaya koymakta olup, yerel yönetimler, üniversiteler, sivil toplum örgütleri vb. kurumların bireylerin bedensel aktivitelerini artırıcı düzenlemeler üzerinde çalışmalarında yol gösterici olmaktadır.

\section{Kaynakça}

Ateş, B. (2016). Üniversite öğrencilerinde akademik başarının yordayıcısı olarak psikolojik iyi oluş ve sosyal yetkinlik. Elektronik Sosyal Bilimler Dergisi, 15(59), 1203-1214.

Bieligmeyer, S., Helmert, E., Hautzinger. M., \& Vagedes, J. (2018). Feeling the sound - short- term effect of a vibroacoustic music intervention on well-being and subjectively assessed warmth distribution in cancer patients-A randomized controlled trial. Complementary Therapies in Medicine, 40, 171-178

Büyüköztürk, Ş., Kılıç Çakmak, E., Akgün, Ö. E., Karadeniz, Ş., \& Demirel, F. (2014). Bilimsel araştırma yöntemleri. Ankara: Pegem Akademi.

Carr, A. (2016). Pozitif psikoloji. İstanbul: Kaknüs Yayınları.

Costigan, S. A., Lubans, D. R., Lonsdale, C., Sanders, T. \& Cruz, B. P. (2019). Associations between physical activity intensity and well-being in adolescents. Preventive Medicine, 125, 55-61. DOI:10.1016/j.ypmed.2019.05.009

Dağ, A., Korkutaata, A. \& Özavcl, R. (2019). Sportif etkinlik işletmelerinde çalı̧an personelin öznel iyi oluş düzeyleri ile yaşam doyumlarının bazı değişkenler açısından incelenmesi. Uluslararası Spor Egzersiz \& Antrenman Bilimi Dergisi, 5(3), 154-162.

Demirci, İ., \& Ekşi, F. (2015) Ergenler için beş boyutlu iyi oluş modeli: EPOCH Ölçeği'nin Türkçe formunun geçerliği ve güvenirliği. Gençlik Araştırmaları Dergisi, 3(3), 9-30.

Demirci, İ., \& Ekşi, F., Dinçer, D., \& Kardaş, S. (2017). Beş boyutlu iyi oluş modeli: PERMA Ölçeği Türkçe Formunun geçerlik ve güvenirliği. The Journal of Happiness \& Well-Being, 5(1), 60-77

Department of Health (n.d) The relationship between wellbeing and health. Retrieved from https://assets.publishing.service.gov.uk/government/uploads/system/uploads/attachment_data/file/295474/Th e_relationship_between_wellbeing_and_health.pdf

Diener, E. (1984). Subjective well-being. Psychological Bulletin, 95, 542-575.

Diener, E. (2009). The science of well-being. the collected works of Ed Diener. Heidelberg London New York: Springer Dordrecht.

Downward, P., \& Rasciute, S. (2011). Does sport make you happy? An analysis of the well-being derived from sports participation, International Review of Applied Economics, 25(3), 331-348. DOI: 10.1080/02692171.2010.511168

D'raven, L. L., \& Pasha-Zaidi,N. (2 016). Using the PERMA Model in the United Arab Emirates. Social Indicators Research, 125(3), 905-933.

Ellison, C. G. (1991). Religious involvement and subjective well-being. Journal of Health and Social Behaviour, 32, 8099.

Greaves, C. J., \& Farbus, L. (2006). Effects of creative and social activity on the health and well-being of socially isolated older people: outcomes from a multi-method observational study. Journal of the Royal Society for the Promotion of Health, 126(3), 134-142.

Hays, T. (2005). Well-being in later life through music. Australasian Journal on Ageing, 24, 2832.

Jin, Y., Carson, V., Pabayo, R., Spence, J, C. Tremblay, M., \& Lee, E. (2019). Associations between utilitarian walking, meeting global physicalactivity guidelines, and psychological well-being among South Korean adolescents. Journal of Transport \& Health, 14, 1-10.

Kardaş, F., \& Yalçın, İ. (2019). Türkiye'de iyi oluş ile ilgili yapılmış araştırmaların sistematik olarak incelenmesi. Kastamonu Education Journal, 27(4), 1423-1433. DOI:10.24106/kefdergi.2799

Khalek, A., \& Ahmed, M. (2009). Religiosity, subjective well-being, and depression in Saudi children and adolescents. Mental Health, Religion \& Culture, 12(8), 803-815. DOI: 10.1080/13674670903006755.

Koç, M., \& Keklik, İ. (2020). Hacettepe Üniversitesi'nde çalışan araştırma görevlilerinin psikolojik iyi oluş düzeylerinin yordanması. Hacettepe Üniversitesi Eğitim Fakültesi Dergisi, 35(1), 107-119. 
Koenig, H. G., McCullough, M., \& Larson, D. B. (2001). Handbook of religion and health. New York: Oxford University Press.

Korkmaz Erdoğruca, N. (2012). Tanrıya bağlanma ve psikolojik iyi olma. Toplum Bilimleri Dergisi, 6(12), 95-112.

Küçük, Ö., Çakıcı, A.(2018). İşyeri kabalığının öznel iyi oluş haline etkisi. İş ve İnsan Dergisi, 5(1), 75-87. doi: 10.18394/iid.368835 e-ISSN 2148-967X

Lee, J., Krause, A. E., \& Davidson, J. W. (2017). The PERMA well-being model and music facilitation practice: Preliminary documentation for well-being through music provision in Australian schools. Research Studies in Music Education, 39(1), 73-89.

Myers, J. E., Sweeney T. J., \& Witmer, J. M. (2000) The Wheel of wellness coniseling for wellness: A holistic model for treatment planning. Journal of Counseling E Developement, 78, 251-266

Öztürk, A., \& Çetinkaya, R. S. (2015). Eğitim fakültesi öğrencilerinin öznel iyi oluş düzeyleri ile tinsellik, iyimserlik, kaygı ve olumsuz duygu düzeyleri arasındaki ilişki. Marmara Üniversitesi Atatürk Ĕ̆itim Fakültesi Ĕ̆itim Bilimleri Dergisi, 42, 335-356.

Panza, G. A., Taylor B. A., Thompson, P. D., White C. M., \& Pescatello, L. S. (2019). Physical activity intensity and subjective well-being in healthy adults. Journal of Health Psychology, 24(9), 1257-1267.

Perma, (n.d). Perma Theory Of Well-Being And Perma Workshops. Retrieved from https://ppc.sas.upenn.edu/learnmorelperma-theory-well-being-and-perma-workshops.

Ploukou, S., \& Panagopoulou, E. (2018). Playing music improves well-being of oncology nurses. Applied Nursing Research, 39. 77-80.

Quinn, P. D., Duckworth, A. L. (2007, May), Happiness and Academic Achievement: Evidence for Reciprocal Causality, Poster Session Presented at the Annual Meeting of the American Psychological Society, Washington, D. C.

Rickard N., S., \& Mcferran, K. (2011). Lifelong engagement with music: benefits for mental health and well-being, Nova Science Publishers, Incorporated, ProQuest Ebook Central, Retrieved from http://web.b.ebscohost.com/ehost/ebookviewer/ebook/bmxlYmtfXzU0MTY4OF9fQU41?sid=702cad54-7dc041ce-afcd-760cd5f81dfa@pdc-v-sessmgr01\&vid=1\&format=EB\&rid=1

Ryff, C. D. (1989). Happiness Is Everything, or Is It? Explorations on the Meaning of Psychological Well-Being. Journal of Personality and Social Psychology, 57 (6), 1069-1081

Sezer, F. (2013). Psikolojik iyi olma durumu üzerine etkili faktörler. NWSA-Education Sciences, 8(4), 489-504.

Sharma, S., \& Singh K. (2019) Religion and well-being: the mediating role of positive virtues. J Relig Health, 58, 119131. https://doi.org/10.1007/s10943-018-0559-5

Singh, K., \& Raina, M. (2019). Demographic correlates and validation of PERMA and WEMWBS scales in Indian adolescents. Child Indicators Research 13, 1175-1186.

https://doi.org/10.1007/s12187-019-09655-1

Tiliouine, H., Cummins, R. A., \& Davern, M. (2009). Islamic religiosity, subjective well-being, and health. Mental Health, Religion \& Culture, 12(1), 55-74.

Tuzgöl Dost, M. (2004). Üniversite öğrencilerinin öznel iyi oluş düzeyleri. (Doktora Tezi, Hacettepe Üniversitesi, Ankara). Erişim adresi:https://tez.yok.gov.tr/UlusalTezMerkezi/tezSorguSonucYeni.jsp

Türkmen, M. (2012). Öznel iyi oluşun yapısı ve ana baba tutumları, özsaygı ve sosyal destekle ilişkisi: Bir model sınaması. Uşak Üniversitesi Sosyal Bilimler Dergisi, 5(1), 41-73.

Türköz, S. \& Şahin Kıralp, F. S. (2019). Öğretmen adaylarının öznel iyi oluş, algılanan sosyal destek ve kendini saklama düzeylerinin incelenmesi. Ondokuz Mayıs Üniversitesi Ĕ̆itim Fakültesi Dergisi, 38(2), 51-66. DOI: 10.7822/omuefd.529526.

Western, M., \& Tomaszewski, W. (2016). Subjective Wellbeing, Objective Wellbeing and Inequality in Australia. PLoS One, 11(10), 1-20. DOI: 10.1371/journal.pone.0163345 https://www.ncbi.nlm.nih.gov/pmc/articles/PMC5047468/

Witter, R. A., Okun, M. A., Stock, W. A., Haring, M. J. (1984). Education and subjective well-being: a metaanalysis. Educational Evaluation and Policy Analysis. 6(2), 165-173.

Yalçın, İ (2014) İyi oluş ve sosyal destek arasındaki ilişkiler: Türkiye'de yapılmış çalışmaların meta analizi. Türk Psikiyatri Dergisi, 25, 1-12.

Yaşar Yılmaz, K., \& Çetinkaya, R. (2019). Eğitim fakültesi öğrencilerinin öznel iyi oluş düzeyleri: Psikolojik ve demografik değişkenlerin rolü. İnönü Üniversitesi Eğitim Fakültesi Dergisi, 20(1), 165-177. DOI: 10.17679/inuefd.3317 